\title{
The importance of proper evidence and identi- fication of metallurgical materials for effective management of the company
}

\author{
Vladimíra Schindlerová1, ${ }^{*}$, Ivana Šajdlerová ${ }^{1}$ \\ ${ }^{1} \mathrm{VŠB}$ - Technical University of Ostrava, Faculty of Mechanical Engineering, 17. listopadu 2172/15, \\ 708 33, Ostrava - Poruba, Czech Republic
}

\begin{abstract}
An important characteristic for efficient management of production systems is the ability of a product, component or material to be tracked. That is, to be assigned with a unique symbol, number, or other code (identifier) that can be traced back both within the production process and to the customer (e. g. when complaining about a defective part). Traceability leads to a cost reduction in eliminating the risks associated with the difficult identification of the material or parts, their handling in pre-production, the manufacturing process, or the storage and sale of finished products to customers. In case of problems, it makes it easier to implement the necessary measures and reduces the time to remedy the situation either within the company or even outside. Individual companies within the Czech Republic usually solve the identification and traceability independently. The paper deals with the results of the analysis of the current state of record keeping and identification of metallurgical materials in selected companies, and presents a proposal for improvement of the current situation in a specific company, especially in the field of work with remaining material.
\end{abstract}

Keywords: Identification, traceability, barcodes, designation of the material

\section{Introduction}

Undoubtedly, the company management is aware of the fact that the resulting effect of economic activities has a significant impact on customers' satisfaction with their products. Efforts to meet the assumed requirements regarding price, quality, availability, delivery speed and reliability are paramount. However, the organization's own management and setting up of individual processes and work with them are also fundamentally involved in the achieved results. Transport, storage and handling employ up to $25 \%$ of the company workers, occupy $55 \%$ of the area and up to $87 \%$ of the time which the material spends in the plant. These activities sometimes account for 15 to $70 \%$ of the total cost of the product and also affect the quality of the product. 3 to $5 \%$ of the material may be damaged by incorrect shipping, handling and storage [1]. Storage and handling in logistics are an important competitive factor.

\footnotetext{
* Corresponding author: vladimira.schindlerova@vsb.cz

Reviewers: Josef Chladil, Jozef Pilc
} 


\section{Methodological base}

Identification is the first step that needs to be done to recognize the particular elements of the system before deciding how they will be further handled.

Identification is a very broad term which is used in various contexts, e.g. in mathematics, citizenship, investigation, media, science and engineering, tracking and inventory management, social sciences. In this sense, identification can be defined as the act of finding out what something (or someone) is. This article deals with the identification connected with tracking of objects (remaining metallurgical materials) in an industrial company.

The remaining material management belongs to the field of inventory management and is certainly one of the areas where there will always be room for further improvements. [2] It can represent a significant source of inefficiency, i.e. wasting, in a wide range of its forms - supplies, surplus material and components, unnecessary manipulation, waiting etc. The main forms of wasting in logistics are described in a number of publications worldwide $[1,3,4,5,6]$. Insufficient or inappropriate identification and traceability can significantly contribute to losses and inefficiency of both the manufacturing process and the duration of non-technological operations as well as the manufacturing system as a whole. Some sources are presented e.g. in [7] and the practice confirms that the proportion of non-technological times (i.e. times which do not add any value to the product), servicing or overhead times in mechanical assembly manufacturing is much higher than the proportion of technological times $(20 \%)$. Inappropriate work with remaining material or with useless supplies of material is the area where a hidden potential to save financial resources of the company can be found.

For any object identification (material, semi-finished products, goods, people etc.), it is essential to have the objects marked properly first of all. We can say, traceability begins with marking of particular parts. Marking and traceability are very important in all fields of business. They are used in aerospace, automotive, military, energy, medical and food industry, metallurgy etc.

We can meet with various marking technologies (see table 1) in industrial practice. The nature of the manufacturing, its repeatability, materials used, manufacturing processes as well as required durability of marking influence the choice of technology used. An important aspect when selecting the technology used is the possibility of using standards for marking and its automation. The costs related to the implementation of the selected technology and, last but not least, the management of the organization, which must provide or release the required resources, also play an essential role.

Identification and Data Capture can be understood as automatic objects identifying, collecting data about them, and entering them into computer systems, without human involvement.

Automatic Identification and Data Capture (AIDC) can be used in different fields of business. There are the enabling AIDC technologies as bar codes - linear and 2D, radio frequency (RFID), optical character recognition (OCR), magnetic stripe, smart card, biometrics, voice recognition or real-time location service (RTLS). The beginning of today's successful AIDC technologies is connected with the names of Bernard Silver and N. Joe Woodland and their patent application "Classifying Apparatus and Method" from 1949 [8], (granted 1952), which introduces the first machine-readable bar code, called the Bull's Eye Code. Currently, there are a huge number of standards for AIDC technologies, which can be implemented in a variety of areas [9]. 
Table 1. Various marking technologies

\begin{tabular}{|c|c|c|c|c|c|c|c|}
\hline \multirow[b]{2}{*}{ Technology } & \multirow[b]{2}{*}{ Description } & \multicolumn{6}{|c|}{ Marking } \\
\hline & & 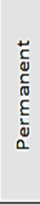 & 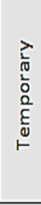 & 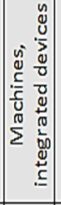 & 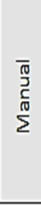 & $\begin{array}{l}\bar{\Phi} \\
\dot{\nu} \\
\dot{n}\end{array}$ & 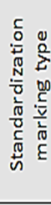 \\
\hline Dot-peen & $\begin{array}{l}\text { Work by electromechanically striking a carbide or diamond stylus assembly against the } \\
\text { surface of a part to be marked. }\end{array}$ & $\checkmark$ & & $\checkmark$ & & $\checkmark$ & $\checkmark$ \\
\hline Scribing & Uses a hardened tip (a diamond or carbide) to mark the surface of components. & $\checkmark$ & & $\checkmark$ & & $\checkmark$ & $\checkmark$ \\
\hline Laser & $\begin{array}{l}\text { A high frequency beam generated from a laser source. This beam is then amplified and } \\
\text { directed towards a part to be marked. }\end{array}$ & $\checkmark$ & & $\checkmark$ & & $\checkmark$ & $\checkmark$ \\
\hline Electrochemical & $\begin{array}{l}\text { By means of a chemical reaction of the electrolyte and the electric current, the mark is } \\
\text { applied over the template to the surface. Marking by oxidation or etching. }\end{array}$ & $\checkmark$ & & $\checkmark$ & $\checkmark$ & $\checkmark$ & $\checkmark$ \\
\hline Hand Stamps & $\begin{array}{l}\text { Marking tools made of high quality steel with a hardness of } 60 \mathrm{HRC} \text {, designed for } \\
\text { marking materials up to a hardness of } 40 \mathrm{HRC} \text {. }\end{array}$ & $\checkmark$ & & & $\checkmark$ & $\checkmark$ & \\
\hline Industrialmarkers & $\begin{array}{l}\text { Ball markers, varnish markers, rigid markers, special markers, water removable markers } \\
\text { for different types of materials. They are not suitable for direct contact with food. }\end{array}$ & $\checkmark$ & $\checkmark$ & & $\checkmark$ & $\checkmark$ & \\
\hline Burner plate & Marking the product with a suitably modified burner plate (e.g. brass). & $\checkmark$ & & & $\checkmark$ & & $\checkmark$ \\
\hline $\begin{array}{l}\text { Electroerosive } \\
\text { pencil }\end{array}$ & The pencil works on the principle of an electric arc. Tungsten electrode. & $\checkmark$ & & & $\checkmark$ & $\checkmark$ & \\
\hline Etching pen & $\begin{array}{l}\text { An indelible description of almost all metal surfaces. Mark resistant to scratches, } \\
\text { abrasion, chemicals, etc. }\end{array}$ & $\checkmark$ & & & $\checkmark$ & $\checkmark$ & \\
\hline Engraving Pen & $\begin{array}{l}\text { Pneumatic or electric hand held engraving pen is simply used like a pen and relies on } \\
\text { the quality of the handwriting. Marking based on micro-impact. }\end{array}$ & $\checkmark$ & & & $\checkmark$ & $\checkmark$ & \\
\hline $\begin{array}{l}\text { Non-contact } \\
\text { marking with } \\
\text { color point }\end{array}$ & The ink is splashed under pressure from the spray gun to the desired location. & $\checkmark$ & $\checkmark$ & $\checkmark$ & & $\checkmark$ & $\checkmark$ \\
\hline
\end{tabular}

\subsection{Identification of remaining material}

A lot of companies have developed standards how to deal with remaining material. They have defined parameters which help them determine whether the waste (scrap) can no longer be used, or the remaining material is worth storing for further manufacturing. Preconditions for further use of remaining material include correct identification, traceability and proper storage. Unless it is possible to find out in a reasonable time what material, in what quantity and quality is available and whether we are able to prepare it (or not) for the manufacturing process quickly and without unnecessary costs, it is advisable to consider the possibility of getting new material and scrapping the residues automatically. In this respect, it is also important to take into account the environmental aspects regarding both the energy intensity for the manufacturing of metallurgical materials and the sustainability of resources for the future.

$$
\sum_{1}^{n} C_{S R M}<\sum_{1}^{n} C_{N M}-\sum_{1}^{n} P_{S C}
$$

$\mathrm{C}_{\mathrm{SRM}}$ - remaining material cost; $\mathrm{C}_{\mathrm{NM}}$ - new material cost; $\mathrm{P}_{\mathrm{SC}}-$ scrap price

To decide on the use of remaining materials, we have to ensure that the costs related to the storage and management of the residues are lower than the costs to acquire new material reduced by an amount of the financial resources gained from selling the scrap.

The basic procedure for working with remaining material is shown in the flowchart (Fig. 1). 


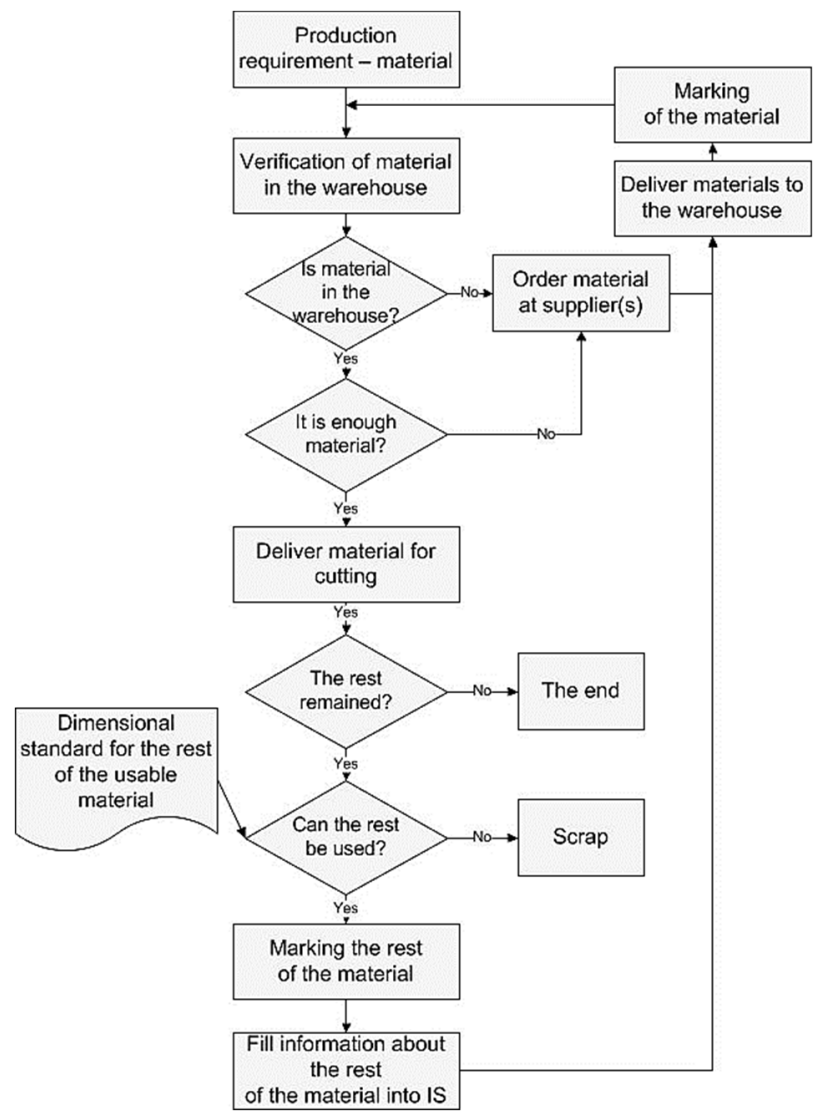

Fig. 1. Flowchart

\section{A Case study of evidence and identification of metallurgical materials}

The presented study deals with a company which is engaged mainly in the production of flame-cut shapes and the sale of thick metal plates on the domestic and foreign markets, and especially with the area of processing the remaining steel material in this company.

\subsection{Survey on the use of automatic identification in several domestic companies}

The study itself was preceded by a survey on the use of automatic identification in several domestic companies. The survey was carried out on a sample of 6 companies with $30-270$ employees which focus mainly on metalworking (e.g. processing of metal plates, profiles, pipes, wires etc.). The survey shows that there is no unified system of automatic identification in domestic industrial enterprises which could be bought as a finished product and implemented easily. It also shows that domestic industrial enterprises want to and make an effort to introduce automatic identification of material, supplies and semi-finished products [10]. 
Other findings include:

- Organizations in the supply chain use different forms of identification (customers demand their own type of marking), it is impossible to use unified marking.

- In most of the monitored companies, dispatch notes were used, mainly for tracking the production process. Apparently, it is based on the experience of domestic industrial enterprises with the given system and on the fact that this system has proved in the long term.

- Some manufacturing processes, such as burning, grinding, blasting, heat treatments, have a common feature: conventional marking doesn't last long.

- Companies which have been using the AI system actively for a longer period (5-6 years) accept it positively. The positives also initiate the introduction of other ideas affecting the production efficiency and the manufacturing system (e.g. the signal semaphores).

- In companies with established AI system, readers and printers are located at each workplace. Therefore, new labels can be printed out either after every operation or as needed.

- The importance of high-quality connection and cooperation between AI and IS in the enterprise is crucial.

- In case the own manufacturing system is designed unsuitably (illogically) and is unnecessarily complicated, errors occur far more often because of its complexity.

- It is the human factor that has been identified as the common denominator of errors in the manufacturing system, whether it was reluctance, ignorance or negligence of employees.

- The stored remaining material can be very diverse mainly in piece or custom-made production, which is specific due to a large amount of orders of one or a few pieces. Appropriate identification of residues and their proper storage considering easy manipulation are essential.

\subsection{Evidence and identification of metallurgical materials in monitored companies}

Based on the results of an inventory check at the end of 2016, almost 1450 tons of steel materials were found in remnants from previous production in store of the monitored company. This amount was estimated at around 19 million CZK which represented approximately $24 \%$ of the total inventory of the enterprise. The material was stored on an area of about $300 \mathrm{~m}^{2}$.

The supplied input material (standardized size sheet) is usually used for the manufacturing of more orders (products) of various sizes and shapes. Part of the material is then scrapped, usable remaining material goes to the stock of remains for further potential production.

The material of many of the stored residues (about $26 \%$ of all residues) couldn't be identified correctly, only the dimensions were obvious. Tests for determining the material in question weren't allowed by the company's management due to their cost. Until the decision of the company's management to keep records of the residues (Excel) and their replanning into new production, the remnants had been only growing. Then, there was a rapid slowdown in their accumulation. The goal of the company's management is to reach the $20 \%$ limit of the current situation of the stored remaining material.

The management decided to invest in a new information system (K2) which also includes the AI module. All the data is now entered into the IS which is shared by all departments and employees of the enterprise with appropriate rights. 


\section{Proposal for the introduction of AI for the identification of remaining material (residues).}

The proposal for the introduction of AI for the identification of remaining material had to respect the fact that the company's products are intended for various customers and create inputs for further processing. Permanent marking or branding weren't allowed in this case. Therefore, matrix data and laser marking of the material can't be applied.

After considering the advantages and disadvantages of AI using barcodes for the company (Table 2), the management decided to implement this type of marking.

Table 2. Various marking technologies

\begin{tabular}{|c|c|}
\hline Advantages & Disadvantages \\
\hline $\begin{array}{ll} & \text { Maturity of Barcodes marking } \\
\text { - } & \text { Small risks associated with Barcodes } \\
\text { marking } \\
\text { - }\end{array}$ & $\begin{array}{l}\text { - Initial higher purchase costs } \\
\text { - Initial more demanding logical planning } \\
\text { (when to identify, location of the readers } \\
\text { and who will identify) } \\
\text { - } \quad \text { Training of employees }\end{array}$ \\
\hline
\end{tabular}

The choice of suitable labels and their testing to find out whether they will adhere to the steel under given conditions were the most important steps.

10 labels were selected to be tested which varied in material they were produced from and used glue. Their shape, size, etc. weren't emphasised. The aim was to test which labels adhere to the rough surface of the sheet in operating and storing conditions (in a shop floor). The price ranged from 0,5 to $4 \mathrm{CZK} / 1$ piece. The tested labels were made of paper, metal and plastic.

A sample of sheet with a maximum amount of dust, mill scales and other impurities was selected for testing.
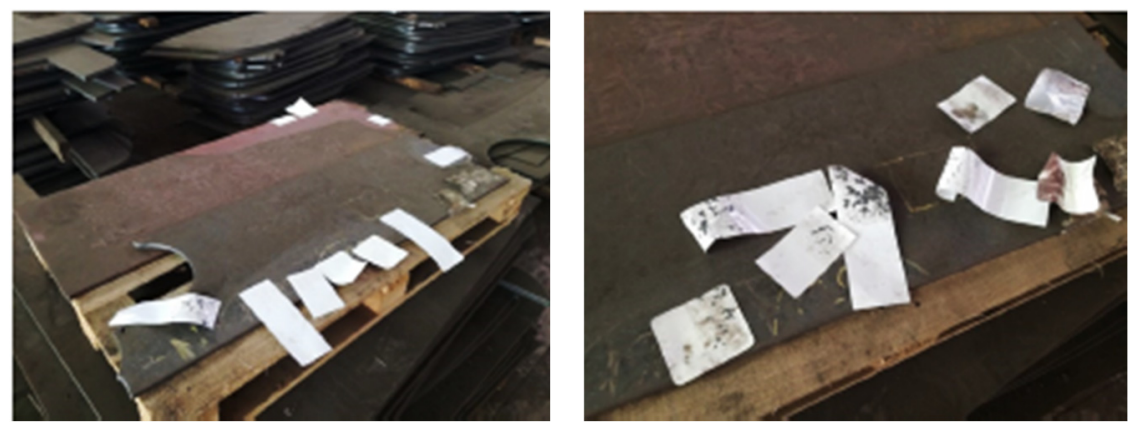

Fig. 2. Tested samples

None of the tested labels adhered to the material without its prior cleaning from dust and dirt. After the material had been cleaned from dust and basic impurities, the labels (concerning the intended use) adhered sufficiently even to the scaled material. They could be torn off the material, leaving the mill scales on the label.

In the following step, the size of the label was decided. Essential was mainly the length of the label. Its overlap had to be sufficient to enable the identification of the material even 
when stacking the material on top of each other. To avoid larger initial investment, the company chose a conventional paper label. The selected label fulfilled the basic requirements, i.e. sufficient adhesion to metal sheet, low cost per item $(0,67 \mathrm{CZK} /$ piece without VAT), availability of labels (are sold commonly), wide range of printers for the chosen label. The disadvantage of the chosen identification method was that it couldn't be used for heat-treated items (metal labels).

It was suggested to divide the backing material of the label into two parts. When applied to the material, only one part is removed and the other remains backed. Thanks to this, the label is tougher and twists less.

The input costs for the implementation depend on the selected AI and the number of particular components. In this case, the costs were approximately $300000 \mathrm{CZK}$ excluding VAT (printer, 9 sensors, 9 computers, portable terminal, programming, labels, marking of material) and only for the equipment which is to be used for remaining material management.

Effective handling with remaining material also involves appropriate storage of this material. Proper marking of the material does not mean that it can be traced easily. In this case, it is advisable to carry out the ABC analysis [6] and, based on the results, spatially arrange the storage of the material in the room available, e.g. using the SLP design methodology [11,12]. E.g. it is possible to create sectors for sheets of $30 \mathrm{~mm}$ or more thickness where the materials can be stored on suitable pallets. Sheets of smaller thicknesses (the company uses them to a small extent) and remnants of circular shape could be placed on shelves. In this case, it is recommended to implement the elements of the $5 \mathrm{~S}$ methodology [6] which is suitable not only for the production itself but also in all sections of the manufacturing system.

It has been proved that the height of costs on AIDC and spatial layout of the storage space is much lower than the means obtained from the sale of the unidentified material residues in the form of scrap (about 5 million CZK excluding VAT). Savings obtained from the use of remaining material for further production represent another approximately 10 million CZK. There is only a one-off cost saving. Order and easily identifiable remaining material in stock provide additional day-to-day savings related to time waiting for material or inappropriate production owing to misplaced material etc.

\section{Conclusion}

The survey of selected companies confirms that domestic industrial enterprises want to and make an effort to introduce automatic identification of material, supplies and semi-finished products.

The achieved results demonstrate that the methods of Automatic Identification and Data Capture can also be successfully implemented into the field of storage of rest (remaining) materials and it is very useful for production spheres which do not have the character of serial or mass production.

The benefit of introducing AI into the company has been proved. The proper work with the remaining material has brought positive results with an impact on the cost, time and efficiency of the production system.

One-off cost savings can vary in double-digit percentage range of the total inventory depending on the initial state of inventory management and remaining material in enterprises. Day-to-day cost savings can vary in single-digit percentage range.

The transition from a familiar system to a new one is conditioned by the supportive approach of the company management and also by its patience. For the proper functioning 
of the newly established system, it is essential to prepare the employees and convince them of the positives of the changes, qualify them appropriately and motivate them so that they could accept the changes and adapt to them.

The implementation in practice has shown that the management support is crucial for successful implementation changings to practice.

\section{References}

1. J. Košturiak, Z. Frolík, Lean and Innovative Enterprise. Praha: Alfa Publishing, (2006)

2. V. Schindlerová, I. Šajdlerová, Influence tool wear in material flow. Adv. In Sci. And Tech.- Res. J. 11, 161-165 (2017)

3. J. K. Liker. The Toyota Way: 14 Management Principles from the World's Greatest Manufacturer. New York: McGraw-Hill, (2004)

4. J. P. Womack, D.T. Jones, Lean Thinking: Banish Waste and Create Wealth in Your Corporation. Simon \& Schuster, (2003)

5. S. Shingo, The Shingo Production Management System: Improving Process Functions. P. Cambridge, MA: Productivity Press. (1992)

6. J. Bhamu, K. S. Sangwan, Lean manufacturing: literature review and research issues. Int. J. of Op. \& Prod. Man., 34, 876-940, (2014)

7. M. Leščišin, V. Líbal, A. Šperlich, Organization and management of production. Bratislava: Alfa, 85. (1985)

8. The History of automatic identification ID systems. (AIDC 100, Rev A, July 9, 2010) Available: http://www.aidc100.org/index.htm

9. Standards catalogue: 35.040.50 - Automatic identification and data capture techniques. (ISO, 2018) Available: https://www.iso.org/ics/35.040.50/x/p/1/u/0/w/0/d/0

10. A. Chmiel, Record Keeping and Identification of Metallurgical Materials: Diploma Thesis. VSB - TUO, Faculty of Mechanical Engineering, Department of Mechanical Technology, (2017)

11. R. Muther, K.Haganäs, Systematic handling analysis (SHA). Management and Industrial Research Publications, Kansas City, (1975)

12. R. Muther, Systematic layout planning (S.L.P.). Boston:Cahners Books (1972) 